\title{
CONSUMULUI CHIMIC DE OXIGEN ÎN APELE RÂULUI PRUT
}

\author{
Anastasia Ivanova \\ Institutul de Zoologie, e-mail: ivanova.asm@gmail.com
}

\begin{abstract}
Rezumat
Consumul chimic de oxigen (COO) a fost determinat în probele de apă din râul Prut pe parcursul anului 2020. Valorile medii ale $\mathrm{CCO}_{\mathrm{Mn}}$ și $\mathrm{CCO}_{\mathrm{Cr}}$ au variat între 3.5 și $9.0 \mathrm{mg} \mathrm{O} / \mathrm{L}(5.5 \pm 1.2 \mathrm{mg} \mathrm{O} / \mathrm{L})$ și de la 12 până la $45 \mathrm{mg} \mathrm{O} 2 / \mathrm{L}(22 \pm 8.7 \mathrm{mg} \mathrm{O} 2 / L)$ respectiv. Analiza rezultatelor demonstrează existența în apele râului Prut a substanțelor organice ușor degradabile (un indicator de poluare proaspătă și permanentă) și celor greu degradabile. Conform cerințelor Regulamentului de calitate pentru apele de suprafață, apa din râul Prut pentru perioada studiată după consumul chimic de oxigen cu mangan este atribuită la clasa de calitate I-II (foarte bună - bună), iar după consumul chimic cu bicromat - la clasa II-III (bună-moderat poluată).
\end{abstract}

Cuvinte-cheie: consumul chimic de oxigen, calitatea apei, râul Prut.

\section{INTRODUCERE}

Valoarea consumului chimic de oxigen (CCO) este pe larg utilizată în investigații ecosistemelor acvatice. Această mărime indirect caracterizează conținutul în apă a substanțelor organice și celor minerale, oxidate de unul din oxidanți puternici în condiții determinate. Consumul chimic de oxigen, se exprimă prin cantitatea necesară oxigenului, pentru oxidarea substanțelor organice într-un anumit volum de apă. În metoda determinării consumului chimic de oxigen în calitate de oxidant se utilizează permanganatul $\left(\mathrm{CCO}_{\mathrm{Mn}}\right)$ sau bicromatul de potasiu $\left(\mathrm{CCO}_{\mathrm{Cr}}\right)$. $\mathrm{Cu}$ ajutorul $\mathrm{CCO}_{\mathrm{Mn}}$ să determină cantitatea substanțelor organice ușor degradabile iar prin determinarea $\left(\mathrm{CCO}_{\mathrm{Cr}}\right)$ - cantitatea compușilor organici, inclusiv și cei greu degradabili. Compoziția substanțelor organice în apele de suprafață se formează în rezultatul mai multor factori. Printre factori naturali se numără procesele de degradare biochimică a resturilor animale și celor vegetale și procesele metabolismului organismelor vii. Substanțele organice pătrund în corpuri acvatice cu scurgerile de pe suprafața bazinului hidrografic, iar sub influența factorilor antropici substanțele organice pătrund în apă prin scurgeri-

https://doi.org/10.53937/9789975151979.05

\begin{abstract}
Chemical oxygen demand (COD) was determined in water samples from the Prut River during 2020. Mean values of $C O D_{M n}$ and $C O D_{C r}$ ranged from 3.5 to $9.0 \mathrm{mg} \mathrm{O} / \mathrm{L}(5.5 \pm 1.2 \mathrm{mg} \mathrm{O} / \mathrm{L})$ and from 12 to 45 $\mathrm{mg} \mathrm{O}_{2} / \mathrm{L}\left(22 \pm 8.7 \mathrm{mg} \mathrm{O} \mathrm{O}_{2} / \mathrm{L}\right)$ respectively. The analysis of the results demonstrates the existence in the waters of the Prut River of easily degradable organic substances (an indicator of fresh and permanent pollution) and those that are difficult to degrade. According to the requirements of the Regulation on the quality of surface waters, the water from the Prut River for the period studied in accordance to the chemical oxygen demand with manganese is assigned to quality class I-II (very good-good), and after chemical oxygen demand with chrome - to class II-III (good - moderately polluted).
\end{abstract}

Keywords: chemical oxygen demand, water quality, Prut river.

le de pe teritoriile urbanizate, agrare și împreună cu apele industriale și cele menajere.

\section{MATERIALE ȘI METODE}

Probele de apă au fost prelevate din râul Prut în următoarele puncte de prelevare: Costești-Stâncă, Braniște, Leușeni, Cahul, Cîșlița și Giurgiulești (port) în perioada expedițiilor sezoniere pe parcursul anului 2020. Apă a fost prelevată la o distanță de 3-5 m de la mal la adâncime $0-50 \mathrm{~cm}$ de la suprafața corpului de apă și adusă în laborator în recipiente din plastic. Determinarea consumului de oxigen a fost efectuată în decurs de 24 de ore din momentul prelevării probelor. Analiza a fost efectuată conform standardelor de stat SM SR EN ISO 8467:2006 și SM SR ISO 6060:2006.

\section{REZULTATE ȘI DISCUṬII}

Valorile medii ale consumului chimic de oxigen cu mangan în apele r. Prut pe parcursul perioadei de studiu au constituit $5.5( \pm 1.3) \mathrm{mg} \mathrm{O}_{2} / \mathrm{L}$ și au va-

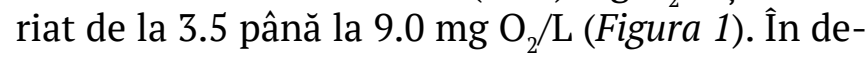


pendență de sezon, valorile medii $\mathrm{CCO}_{\mathrm{Mn}}$ au constituit: iarnă $6.4( \pm 0.52) \mathrm{mg} \mathrm{\textrm {O } _ { 2 }} / \mathrm{L}$, primăvară -4.8 $( \pm 0.11) \mathrm{mg} \mathrm{O} \mathrm{O}_{2} / \mathrm{L}$, vară $-6.6( \pm 1.4)$ și toamnă -4.3 $( \pm 0.64) \mathrm{mg} \mathrm{O}_{2} / \mathrm{L}$. În luna iunie după ploi abundente au fost prelevate probele de apă în punctele Criva, Costești, Braniște, Leușeni, unde valoarea medie $\mathrm{CCO}_{\mathrm{Mn}}$ a constituit $7.0( \pm 1.9) \mathrm{mg} \mathrm{O} / \mathrm{L}$, și a fost mai mare în comparație cu $\mathrm{CCO}_{\mathrm{Mn}}$ din probele prelevate în alte condiții anului 2020. Mărimea consumului chimic cu mangan în apele râului Prut a fost con- siderată ca mică (2-5 mg $\left.\mathrm{O}_{2} / \mathrm{L}\right)$ - medie $(5-10 \mathrm{mg}$ $\left.\mathrm{O}_{2} / \mathrm{L}\right)$ [1]. Valoarea medie a $\mathrm{CCO}_{\mathrm{Cr}}$ pentru perioada de studiu a constituit $22 \pm 8.7 \mathrm{mg} \mathrm{O} / / \mathrm{Lssi}$ a variat de la 12 până la $45 \mathrm{mg} \mathrm{O}_{2} / \mathrm{L}$ (Figura 1). $\mathrm{O}$ creștere a valorilor $\mathrm{CCO}_{\mathrm{Cr}}$ a fost înregistrată în probele prelevate în luna februarie și octombrie pe secțiunea Leușeni - Giurgiuleși, atingând valorile maximale în punctul Giurgiulești (45 $\mathrm{mg} \mathrm{O} / 2$ Lîn luna februarie și $28 \mathrm{mg} \mathrm{O}_{2} / \mathrm{L}$ - toamnă).
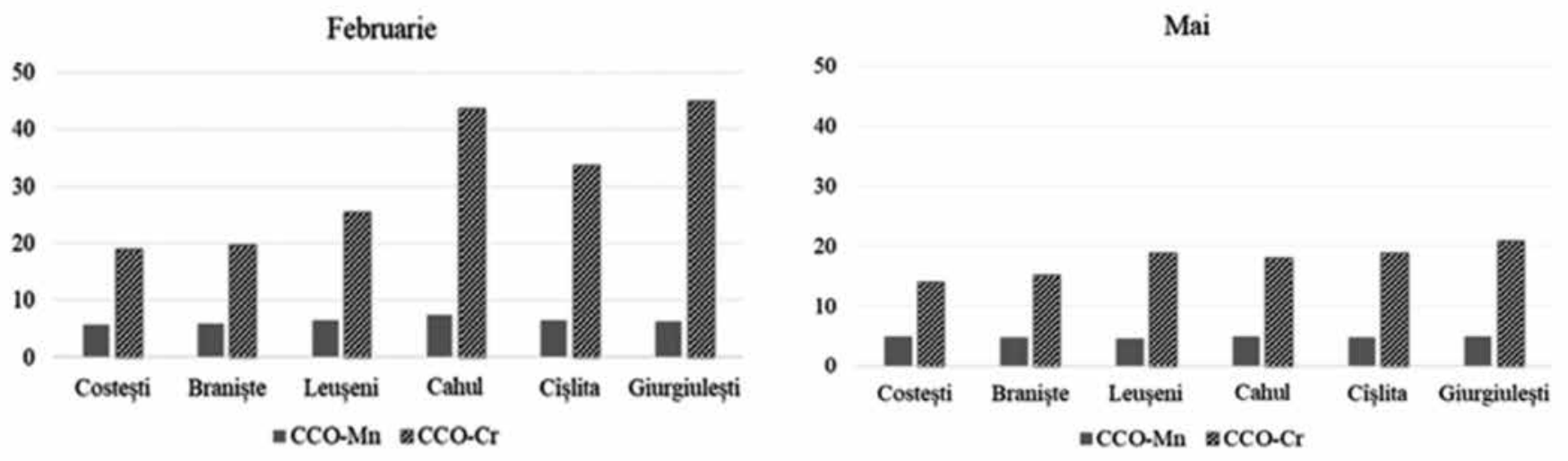

Iulie

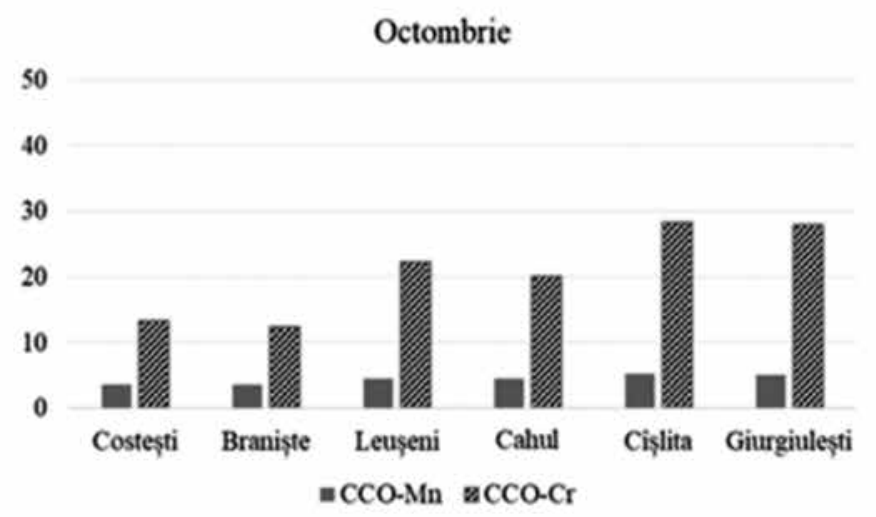

Fig. 1. Valorile consumului chimic de oxigen $\left(\mathrm{CCO}_{\mathrm{Mn}}\right.$ și $\left.\mathrm{CCO}_{\mathrm{Cr}}\right)$ în apele râului Prut în timpul anului 2020.

În comparație $\mathrm{cu}$ creșterea valorilor $\mathrm{CCO}_{\mathrm{Cr}}$ pe secțiunea Leușeni - Giurgiulești, valorile $\mathrm{CCO}_{\mathrm{Mn}} \mathrm{au}$ crescut doar ușor, ceea ce indică despre prezența în apă într-o cantitate ridicată a substanțelor organice greu degradabile. Această creștere a valorilor $\mathrm{CCO}_{\mathrm{Cr}}$ probabil este influențată de apele râului Jijia - un afluent de dreaptă, care se revarsă în Prut în amonte de punctul de prelevare Leușeni și de asemenea, de influența apelor uzate. De menționat că valori similare ale $\mathrm{CCO}_{\mathrm{Cr}}$ au fost înregistrate în râul Jijia în perioada de investigații 2010-2016, unde

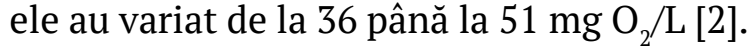

Dinamica consumul chimic de oxigen este legată de regimul hidrologic și hidrobiologic, transportul substanțelor organice de pe teritoriului bazinului hidrografic și de factorii antropici. Dis- tribuirea materiei organice în apele râurilor este legată de particularitățile fizico-geografice locale. Formarea și distribuirea materiei organice și componenților ei depinde în primul rând de condiții generale ale formării și dezvoltării landșaftului [1]. Conform rezultatelor cercetărilor diferitor zone geografice, zonelor de silvostepă și stepă le sunt caracteristici valori medii anuale ale $\mathrm{CCO}_{\mathrm{Mn}}$ în diapazonul de 6.6 - $10.1 \mathrm{mg} \mathrm{O}_{2} / \mathrm{L}$ și valori medii ale $\mathrm{CCO}_{\mathrm{Cr}}$ în diapazonul între 20 și $30 \mathrm{mg} \mathrm{O} / \mathrm{L}$ [1]. Rezultatele studiului nostru sunt similare $\mathrm{cu}$ aceste valori. Dar trebuie de ținut cont de faptul că astăzi factorii antropici au o influență foarte puternică asupra ecosistemelor acvatice și această influență trebuie să fie luată în considerație în timpul analizei rezultatelor. 
Raportul $\mathrm{CCO}_{\mathrm{Mn}} / \mathrm{CCO}_{\mathrm{Cr}}$ și $\mathrm{CCO}_{\mathrm{Mn}} / \mathrm{C}_{\text {org }}$ se utilizează la caracterizarea conținutului materiei organice și a gradului ei de transformare [3]. Valoarea medie a concentrației materiei organice pe sectorul Costești-Stîncă - Giurgiulești pentru perioada de studiu a fost întru-un interval de la 12 până la $21 \mathrm{mg} / \mathrm{L}$ și în mediu a constituit $17 \pm 3.6$ mg/L. Relația procentuală a mărimii consumului chimic de oxigen cu permanganat către mărimea consumului chimic de oxigen cu bicromat $\left(\mathrm{CCO}_{\mathrm{Mn}} / \mathrm{CCO}_{\mathrm{Cr}} \cdot 100 \%\right)$ a variat între 14 și $45 \mathrm{cu}$ valoarea medie de 27 , ceea ce indică asupra faptului că în apele râului Prut pe secțiunea studiată sunt prezente substanțe organice ușor degradabile (indicator de poluare proaspătă și permanentă) și substanțe greu degradabile. De asemenea, despre predominarea a materialului organic proaspăt format vorbește și raportul $\mathrm{CCO}_{\mathrm{Mn}} / \mathrm{C}_{\text {org }}$ mai mic de 1 în probele analizate.

Conform Regulamentului cu privire la cerințele de calitate a mediului pentru apele de suprafață (Tabel 1), apele din râul Prut pe parcursul perioadei studiate, conform consumului chimic de oxigen cu mangan se referă la clasa I-II de calitate (foarte bună - bună) preponderent bună, (Tabel 2). În unele locuri de prelevare (Cîșlița și Giurgiulești) și anumite condiții (ex. după ploi abundente) apa era clasificată ca moderat poluată (clasa III). Conform cerințelor de calitate după consumul de oxigen cu bicromat, apa din r. Prut s-a încadrat în limitele clasei a II-III (bună - moderat poluată) preponderent moderat poluată. În perioada lunii februarie când debitul apei a fost scăzut apa a fost clasificată ca moderat poluată - poluată (clasa III-IV), (Tabel 1,2).

Tabelul 1. Cerințele de calitate a mediului pentru apele de suprafaţă. HG Nr. 890 din 12.11.2013

\begin{tabular}{|c|c|c|c|c|c|c|}
\hline Parametru & Unitate & $\begin{array}{c}\text { Clasa I } \\
\text { (foarte bună) }\end{array}$ & $\begin{array}{c}\text { Clasa II } \\
\text { (bună) }\end{array}$ & $\begin{array}{c}\text { Clasa III } \\
\text { (moderat poluată) }\end{array}$ & $\begin{array}{c}\text { Clasa IV } \\
\text { (poluată) }\end{array}$ & $\begin{array}{c}\text { Clasa V } \\
\text { (foarte poluată) }\end{array}$ \\
\hline $\mathrm{CCO}_{\mathrm{Mn}}$ & $\mathrm{mg} \mathrm{O} / \mathrm{L}$ & $0-5$ & $5-7$ & $7-15$ & $15-20$ & $>20$ \\
\hline $\mathrm{CCO}_{\mathrm{Cr}}$ & $\mathrm{mg} \mathrm{O}_{2} / \mathrm{L}$ & $0-10$ & $10-15$ & $15-30$ & $30-90$ & $>90$ \\
\hline
\end{tabular}

În urma ploilor abundente în luna iunie a fost analizată apa din punctul Criva situat la nordul republicii, în care s-au înregistrat valori ale $\mathrm{CCO}_{\mathrm{Mn}}$ și $\mathrm{CCO}_{\mathrm{Cr}}$ aproape de două ori mai mari (10 și 43 $\mathrm{mg} \mathrm{O}_{2} / \mathrm{L}$ respectiv) decât valorile stabilite pentru punctele de prelevare în aval. Apa din acest punct a fost atribuită la clasa a III-a de calitate - moderat poluată, după indicele $\mathrm{CCO}_{\mathrm{Mn}}$ și la clasa a IV - po- luată, după indicele $\mathrm{CCO}_{\mathrm{Cr}}$. Este interesant de menționat, că în proba de apă din Criva în suspensii predomină fracția organică, ceea confirmă valori ridicate ale consumului chimic de oxigen, cauzate de scurgerea substantelor organice de pe suprafața bazinului hidrografic împreună cu apele uzate și cele menajere în urma ploilor abundente.

Tabelul 2. Clasificarea apei din r. Prut conform cerințelor de calitate pentru apele de suprafață după parametrul consumului chimic de oxigen cu mangan/cu bicromat

\begin{tabular}{|c|c|c|c|c|c|c|}
\hline Prut & Costești & Braniște & Leușeni & Cahul & Cîșliță & Giurgiulești \\
\hline Februarie & II/III & II/III & II/III & II/IV & II/IV & II/IV \\
\hline Mai & $I / I I$ & I/III & $I / I I I$ & $\mathrm{I} / \mathrm{III}$ & $\mathrm{I} / \mathrm{III}$ & $\mathrm{I} / \mathrm{III}$ \\
\hline Iunie & $I I / I I I$ & II/III & II/III & n.a. & n.a. & n.a. \\
\hline Iulie & $\| I I I I$ & II/II & II/II & n.a. & III/III & III/III \\
\hline Octombrie & $\mathrm{I} / \mathrm{II}$ & $1 / 11$ & I/III & I/III & II/III & II/III \\
\hline
\end{tabular}

n.a. - nu a fost analizat 


\section{CONCLUZII}

Rezultatele analizelor probelor de apă din râul Prut pe secțiune studiată au demonstrat că valorile consumului chimic de oxigen cu mangan au variat slab pe întreagă perioadă de studii, alcătuind în mediu $5.5 \pm 1.2 \mathrm{mg} \mathrm{O}_{2} / \mathrm{L}$. Valorile consumului chimic de oxigen cu bicromat au variat mai puternic în comparație cu cele ale $\mathrm{CCO}_{\mathrm{Mn}}$ alcătuind în mediu $22 \pm 8.7 \mathrm{mg} \mathrm{O}_{2} / \mathrm{L}$. Raportul procentual $\mathrm{CCO}_{\mathrm{Mn}} / \mathrm{CCO}_{\mathrm{Cr}}$ între 14 și 45 indică asupra prezenței în apele Prutului substanțelor proaspete puțin transformate ușor degradabile și de asemenea substanțelor greu degradabile. Conform cerințelor de calitate pentru apele de suprafață, apa din râul Prut în perioada analizată a fost atribuită clasei I-II de calitate după indiceele $\mathrm{CCO}_{\mathrm{Mn}}$ (foarte bună - bună) și după indice $\mathrm{CCO}_{\mathrm{Cr}}$ la clasa II-III de calitate (bună - moderat poluată).

Investigațiile sunt realizate în cadrul proiectului 20.80009.7007.06 "Determinarea schimbărilor mediului acvatic, evaluarea migrației și impactului poluanților, stabilirea legităților funcționării hidrobiocenozelor și prevenirea consecințelor nefaste asupra ecosistemelor" (Programul de Stat 2020-2023).

\section{REFERINȚE}

1. НИКАНОРОВ, А.М. Гидрохимия: Учебник.-2-е изд., перераб. и доп. СПб: Гидрометеоиздат, 2001, p.444.

2. ROMANESCU, G., PASCAL, M., PINTILIE MIHU, A., STOLERIU, C.C., SANDU, I. AND MOISII, $M$. Water quality analysis in wetlands freshwater: common floodplain of Jijia-Prut Rivers. Rev. Chim. 68(3), Bucharest, 2017, pp.553-561.

3. РИЖИНАШВИЛИ, А.Л. Показатели содержания органических веществ и компоненты карбонатной системы в природных водах в условиях интенсивного антропогенного воздействия. Вестник Санкт-Петербургского университета. Серия 4. Физика. Химия, (4),2008. 